\title{
Farm Test for Rapid Identification of Antibiotic Residues in Raw Milk
}

\author{
Clarissa V Cardoso ${ }^{1,2}$, Elenice L de C Nunes ${ }^{3}$, Eunice V Barbosa ${ }^{1,2}$, Alcir das G P Ribeiro ${ }^{2}$, Rossiane de M Souza ${ }^{2}$, \\ Maíra H T Liberal ${ }^{2}$ and Helena Carla Castro ${ }^{1 *}$
}

${ }^{1}$ Programa de Pós-Graduação em Ciências e Biotecnologia, Instituto de Biologia, Universidade Federal Fluminense,Brazil

${ }^{2}$ Centro Estadual de Pesquisa em Sanidade Animal, Empresa de Pesquisa Agropecuária do Estado do Rio de Janeiro, Brazil

${ }^{3}$ Secretaria do Estado de Agricultura, Pecuária, Pesca e Abastecimento,Brazil

Submission: January 23, 2019; Published: February 28, 2019

*Corresponding author: Helena Carla Castro - Departamento de Biologia Celular e Molecular, 24020-150, Niterói, Rio de Janeiro, Brazil

\begin{abstract}
Bovine mastitis is the most frequent disease in dairy cattle, which requires the use of antibiotics to control and prevent new infections. However antibiotic drug use in food-producing animals may leave potentially toxic waste, especially when improperly administered. Thus, continuous monitoring of the maximum level of antimicrobial residues in milk is important to avoid risks to human health and interference in the industrial process of dairy products. In this work we compared the efficacy of two on-farm screening tests, SNAP duo beta-tetra ST test and Eco test BT, for the qualitative detection of beta-lactam and tetracycline residues in milk. We analyzed 254 milk samples from Rio de Janeiro state in Brazil, one of the largest milk producers, and our data showed negative results for the animals not treated for bovine mastitis. However, the animals treated with ampicillin and cloxacillin was positive for beta-lactam residues in all samples tested, in both kits. Eco test BT showed false positive results for betalactam residues in mixed milk samples from two untreated animals in two different herds. This may be due to the presence of antibiotics, but also other substances that may interfere with the test (eg. bacteria or somatic cells). Our results confirmed that the SNAP duo beta-tetra ST test could be a useful tool for detecting antimicrobial residues in milk on farm. Eco test BT that should be analyzed in the future.
\end{abstract}

Keywords: Bovine mastitis; Beta lactamics; tetracycline residues; Public Health

Abbreviations: PNCRC: Plan for Control of Residues and Contaminants; MAPA: Ministry of Agriculture; SCC: Somatic Cells Count; UHT: Ultra High Temperature; MRL: Maximum Residue Limit; HPLC: High-Performance Liquid Chromatography;

\section{Introduction}

Bovine milk is the most consumed animal-origin food in several countries. These include Brazil, which is one of the highest producers in the world. Due to its nutritional value, the milk is among the most important agriculture products on daily feeding, contributing to income and employment generation worldwide [1].

In order to protect the consumers, cow milk must be free from harmful substances and microorganisms (e.g. antibiotics and bacteria) [2]. Thus, the quality is not defined only by milk characteristics but also by all factors related to dairy processing and production that can affect the final product [3].

One of the most frequent diseases in world dairy cattle is bovine mastitis., which is characterized by an inflammatory process of the mammary gland, it directly interferes in milk productivity, both in quantity and quality levels [4]. Bacteria are the most common causing agents of bovine mastitis, causing intramammary infection through the teat canal by ascending route [5]. The mastitis bovine control is based on preventing new infections. It requires an expensive treatment with antimicrobials use and/or animal disposal [6]. Thus, antimicrobial therapy is not only a part of a main control program but also an important strategy for elimination of mastitis in the dairy herd [7].

The use of antimicrobials demands the discard of all milk from treated animals. It cannot be sold due to antibiotic metabolites and residues [8]. And antibacterial is thermoresistant profile even against heat treatment of Ultra High Temperature treatment (UHT) or pasteurization [9]. The presence of antibacterial residues in milk is a risk to human health, which includes teratogenic alterations, intestinal flora disorders, allergic reactions and anaphylactic shock. Moreover, these molecules may lead to antibiotic resistance development in the human intestinal tract [10]. They also interfere in the dairy industrial process with significant economic loss (e.g. decrease 
of culture growth of lactic ferments used in yogurt and cheese productions) [11].

In order to ensure the consumers health, there are several production parameters related to the presence of each antibiotic in food. These parameters include safety drug, tolerance or Maximum Residue Limit (MRL), defined as the maximum concentration allowed in food from animals, after the preestablished withdrawal period [12]. As the Brazilian national limits have not been defined, the levels of antimicrobial residues in Brazil are from international references [13].

The antimicrobial drug residue levels in milk are determined by using qualitative and/or quantitative tests, within analytical quality control procedures $[14,15]$. In this context, there are several qualitative kit tests commercially available to detect antimicrobial residues in milk samples. Among these tests there are SNAP duo beta-tetra ST test and Eco test BT. The SNAP duo beta-tetra ST test is a rapid screening enzymatic test optimized for the detection of antimicrobials beta lactam and tetracycline in milk. Interestingly, there is no need for using heat block, sample incubation or reader equipment, with simple visual interpretation. The test can evaluate commingled cow milk and reconstituted powdered milk being designed for simple, easy use conditions with a fast-total assay time of approximately 7 minutes [16].

Similarly, the Eco test BT is an immunoassay for the detection of antibiotics beta lactam and tetracycline in milk samples. According to the manufactures, it can be used on-farm at room temperature in different stages of the dairy production chain for daily detection or in laboratories for analysis of milk samples in series, using the same protocol. Similar to SNAP duo, it has simple visual interpretation, with no need of equipment. The possibility of rapid detection of residues of antibiotics in milk, still on the farm, is of great importance for public health and for the dairy industry; avoiding the contamination of milk without residue. Our objective was to evaluate two enzymatic immunoassays on the farm, called SNAP duo beta-tetra ST and Eco test BT, in the determination of the presence of beta-lactam residues and tetracyclines in raw cow's milk samples, comparing their performance.

\section{Material and Methods}

Milk samples. The collection of biological material from the cattle studied was done following the Protocol of Execution approved by the "Ethics Commission for Animal Use" of the Centro Estadual de Pesquisa em Sanidade Animal Geraldo Manhães Carneiro (CEUA / CEPGM), of the Empresa de Pesquisa Agropecuária do Estado do Rio de Janeiro (PESAGRO-RIO), Protocol Research Project No. 001/2015. In this study we evaluated 254 milk samples collected from 64 cows in five dairy herds located in two cities of the Brazilian State of Rio de Janeiro, from October 2013 to October 2014.

\section{The milk samples were aseptically collected after}

a. Cleaning teats and the adjacent flank areas with $70 \%$ alcohol

b. Drying with sanitary paper towel, and

c. Discarding a few streams of milk. Rural property profile.

\section{The questionnaire was applied to dairy farmer's owners and milkers to analyze}

a. Hygienic sanitary procedures adopted during milking

b. Number of milking per day

c. Type of animals feeding

d. Diseases history

e. Techniques applied for diagnosis of bovine mastitis, and

f. Type and dosage of antibiotics used in the herd.

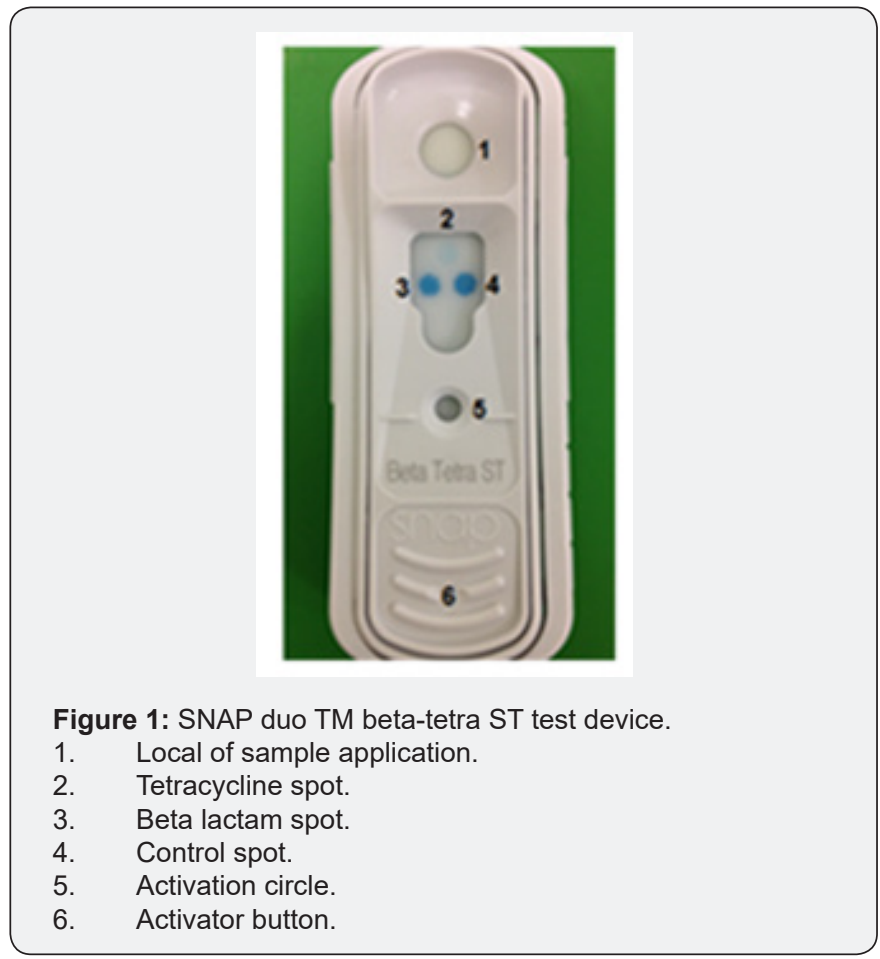

The figure shows a positive result for tetracycline, represented by the tetracycline spot lighter than the control spot.

Detection of antimicrobial residues (on-farm). In order to avoid waste of materials and reagents and to reduce cost in the evaluation, first we analyzed mixed milk samples from four teats of each cow and only in case of a positive result, the test was performed with the individual milk sample of each teat. In this study we chose to analyze the presence of residues of beta lactam and tetracycline antimicrobials in cow milk, due to the frequent use in the bovine mastitis treatment. The antimicrobials Amoxicillin - 4mg/kg (SANDOZ GmbH, Paraná, Brazil), and 
Terramycin - 100mg/mL (Laboratórios PFIZER Ltda., São Paulo, Brazil) were used as controls. They were mixed with pure milk and tested in the same conditions of the other samples. We also tested milk samples with all antibiotics controls mixed. SNAP duo beta-tetra ST test. SNAP duo beta-tetra ST test (IDEXX Laboratories Inc, Maine, USA) is an enzyme-linked receptorbinding assay used to detect both beta lactam and tetracycline residues in raw commingled cow milk samples. In this study, before testing, the milk sample was thoroughly mixed and then $450 \mu \mathrm{L}$ of milk was added to the conjugate tube test. The tube was gently shaked side to side, no longer than 15 seconds, to complete dissolution of the lyophilized enzyme reagent pellet. All content of sample tube was poured into the sample cup of the SNAP duo test (Figure 1).

Once the blue color in the activation circle of the device began to disappear, the activator button was pressed down firmly in accord to the manufacture instructions. SNAP duo device was kept in a horizontal position for 6 minutes and the test result was interpreted visually by comparing the color intensity. The color of the antimicrobial spot lighter than the control spot, indicated the positive result. Eco test BT. Eco test BT (Eco Diagnóstica, Minas Gerais, Brazil) is consisted of disposable pipettes, plastic mini tubes, support for mini tubes and strips. We followed the protocol by adding $200 \mu \mathrm{L}$ of a milk sample to the mini tube using the disposable pipette. Then, we mixed the solution until all the reagents were completely dissolved, leading to the appearance of a pink color. The strip was inserted into the mini tube for $5 \mathrm{~min}$ for sample migration and kept until the result was interpreted.

According to the manufactures, Eco test BT shows three lines: the first line refers to the negative control (milk without antibiotics), the second line to the beta lactam and the third line, tetracycline. The test is valid for the antibiotic tested when the control line appears but not the antibiotic. Otherwise, the test should be considered invalid (Figure 2). Eco test BT is an immune assay based on the binding formation between the colloidal gold-antibody complex with the antibiotics present in the sample. In the test zone, any free colloidal gold-antibodies is retained by the membrane, forming visible line in the test region.

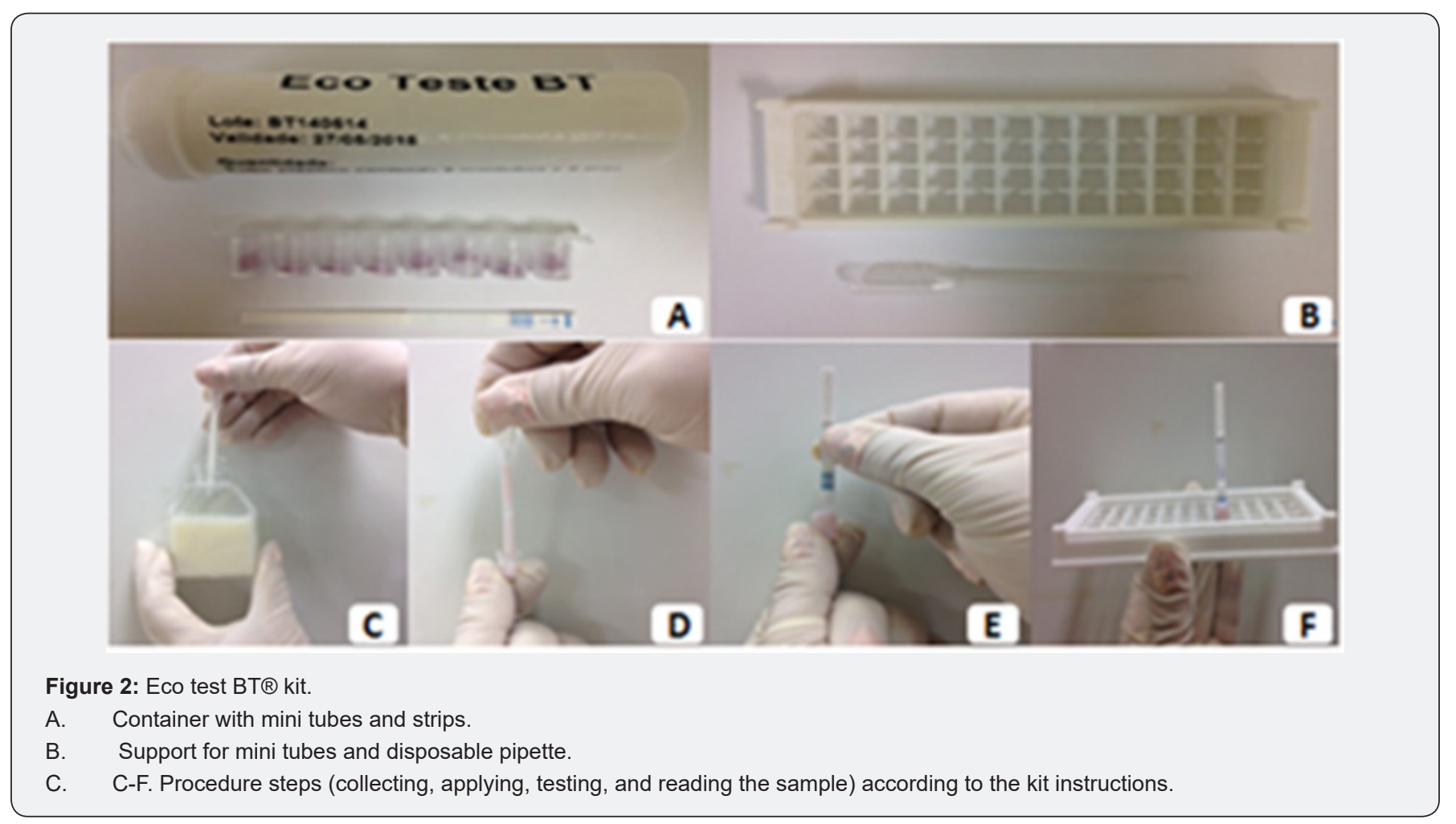

\section{Results}

The SNAP duo beta-tetra ST test and the Eco test BT data showed no positive results for beta lactam and tetracycline residues in cow milk from the four dairy herds. This is in accord to the information about no animals treated in those farms with antibiotic therapy during and/or prior lactations from the questionnaire analysis answered by the rural owners. In the fifth dairy farm, the results of both SNAP duo beta-tetra ST test and Eco test BT indicated presence of beta lactam residues in the mixed milk from four cows, confirmed by the analysis of the 16 individual milk samples obtained from each teat of these four animals (Figure 3). The owner reported that these cows were treated for bovine mastitis with ampicillin $(250 \mathrm{mg})$ and cloxacillin (500 mg). No residues of antibiotics were detected in other animals from this farm. 


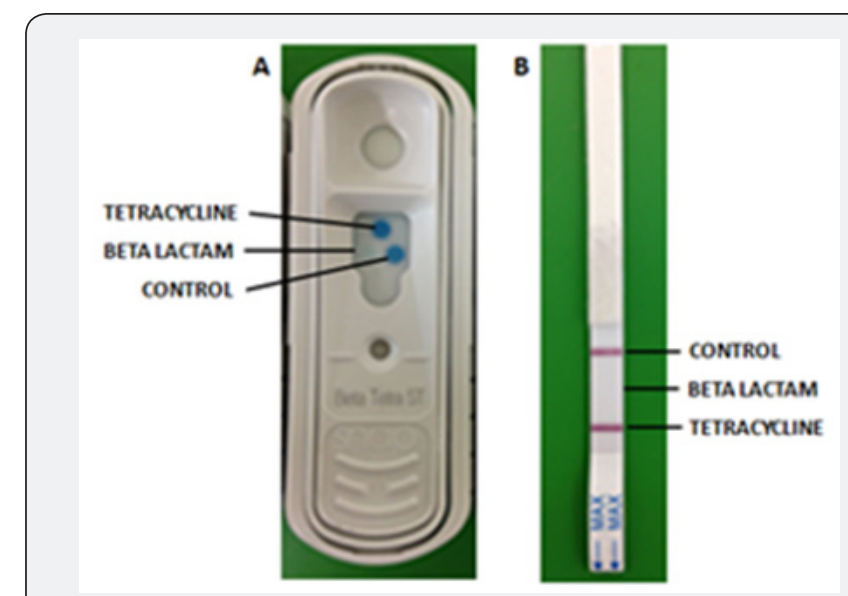

Figure 3: Analysis of a positive beta lactam cow milk sample using SNAP duo TM beta-tetra ST test

A. Eco test $\mathrm{BT} \circledast$

B. The negative control and tetracycline spots or lines are observed indicating no reaction detected. In case of both tests, the absence (spot or line) represents detection of beta lactams residues in milk sample.

However, no tetracycline residues were identified by using both tests in all evaluated dairy herds. The analysis using Eco test BT showed false positive results to beta lactam residues in mixed milk samples from two animals without antibiotics treatment in two different dairy herds. The test was repeated with the individual milk samples from each teat. The result obtained was negative, similar to the results from SNAP duo beta-tetra ST test. The positive (milk with amoxicillin and/or terramycin) and negative (milk without antibiotics) control confirmed the experimental data procedures as expected.

\section{Discussion}

The antimicrobial therapy has a key role in bovine mastitis control programs and on eliminating the disease in the dairy herd [17]. However, the presence of antibacterial residues is the main chemical contamination that concerns associated with treatment bovine mastitis present in the marketed milk and dairy products [10]. Based on this context, programs involved on regulation of dairy production chain and related products as well as milk consumers are increasingly concerned with food security. They demand quality for allowing marketing dairy safe products [18]. On that perspective, the on-farm screening tests may represent useful tools in the dairy industry to detect antibiotic residues to reduce risks of milk contamination [15].

Most of the commercially available tests are qualitative (screening tests), with detection of positive or negative results, depending on a predetermined limit concentration for a specific drug. They include Beta Star plus [19], Charm MRL-3 test $[20,21]$, Copan, Delvotest SP $[16,22]$, and SNAP. On the other hand, quantitative methods have been successfully applied to determine of drug multiresidues in bovine milk samples [23]. The most commonly used technique is the High-Performance
Liquid Chromatography (HPLC) preceded by different extraction steps. It presents specificity and accureness for analyzing a large number of samples per day [24,25]. However, this strategy needs equipment's and technicians fully trained to their execution. Thus, in general, they are only used to confirm the qualitative test [14].

In this study we analyzed the SNAP duo beta-tetra ST test and the Eco test BT, two qualitative tests. They were selected to on-farm evaluation due to the easiness and simplicity of their protocol and ability to detect antimicrobial residues in raw milk samples. Thus, we performed an initial qualitative analysis of the mixed milk samples from all teats of each cow from five different dairy herds of Rio de Janeiro state to detect the animals with antibiotic residues in milk. Samples with positive results were evaluated separately (individual milk samples of each teat) for confirmation, lowering costs and wastes. Accordingly, data from mixed milk samples from animals without antibiotics treatment showed negative results to beta lactam and tetracycline residues in both SNAP duo beta-tetra ST test and Eco test BT tests. The result was similar for dairy herd treated with beta lactams for bovine mastitis by intramamary application. Both SNAP duo betatetra ST test and Eco test BT indicated presence of beta lactam residues in mixed milk samples, confirmed by separate analysis of each teat milk. These data are in accord to the literature that refers to beta lactams as the most commonly antibiotics used to treat mastitis in dairy herds, and the most frequently detected in milk [15,26,27].

\section{In this research, all data are in agreement with the current literature where other researchers evaluated different SNAP test devices for screening on}

a. Beta lactam, tetracycline, and Cefapirin residues in powdered cow milk [28]

b. Tetracycline, beta lactam and sulfonamide residues in waste cow milk [15], and

c. Beta lactam residues in raw cow milk samples [16,29].

The ability of SNAP duo beta-tetra ST test to detect ampicillin and cloxacillin residues in milk is of $4 \mathrm{ppb}$ (parts per billion) and $6 \mathrm{ppb}$, respectively, whereas Eco test BT presents detection limits of $4 \mathrm{ppb}$ to ampicillin and $8 \mathrm{ppb}$ to cloxacillin, according to the manufacturers. For the ampicillin, the tests were within the tolerated concentration defined by the legislation (4 ppb), whereas the cloxacillin residues showed much smaller values than the maximum limit established (30 ppb) [13].

Currently in Brazil, two national programs have monitored the levels of drug residues in foods from animals, including Program of Analysis of Residues of Veterinary Drugs in Foods (PAM Vet) of the National Health Surveillance Agency (ANVISA), coordinated by the Ministry of Health; and the National Plan for Control of Residues and Contaminants (PNCRC), coordinated by the Ministry of Agriculture (MAPA) [12, 30]. 
The absence of tetracycline residues in the milk of all tested animals is similar to that of ANVISA regulation that reported no detection of tetracycline residue in milk in the period 2009/2010 [31]. PNCRC program reported just one milk sample with oxytetracycline above the established limit in 2012 [5], as low as Prado et al. [32], that reported only $2 \%$ occurrence of tetracycline in Brazilian milk above the maximum residue limit. Therefore, since both on-farm tests used in this study had equal results, our data reinforced the low risk for the milk consumers related to the presence of tetracycline residues in milk. The lowest concentration of tetracycline residues detected by the SNAP duo beta-tetra ST test is of 35-50 ppb, lower than $60 \mathrm{ppb}$ of Eco test BT. Interestingly, a detection capability for tetracycline in both tests is below the maximum residue limit of $100 \mathrm{ppb}$ established by legislation [13], leading to more safeness to the consumers. However, it is important to notice that the dairy industry is obliged to produce milk free from any antimicrobial residues.

Our study detected false positive results by using Eco test BT in two milk samples from two animals in different dairy herds. These cows were not treated with antibiotics according to the milk producers and when the test was repeated with individual milk samples, the result was negative. A possible explanation for these data is the presence of substances in the milk that may interfere with the test (e.g. high concentration bacterial or somatic cells) [3]. Indeed, Somatic Cells Count (SCC) was more than 500,000 cells $\mathrm{mL}-1$ in these milk samples, suggesting an intramammary infection. SCC corresponds to the concentration of epithelial cells and leukocyte in milk, which are the udder first line of defense against bacterial invasion [33]. Importantly no interference was observed in free antibiotic milk samples analyzed by the SNAP duo beta-tetra ST test with no evidence of false positive results.

\section{Qualitative tests have great advantages including}

$\begin{array}{ll}\text { a. } & \text { Simple use } \\ \text { b. Fast results } \\ \text { c. Visual analysis }\end{array}$

d. Single package with all items necessary to run and interpret.

However, when detection of antimicrobial residues is below the established limits is advantageous for the consumers but not for the producers. This is due to the fact that the qualitative test may present a result positive in the milk samples with antimicrobial concentrations allowed by the legislation, leading to producer penalization and milk disposal, despite the concentrations are within legal standards [8]. Therefore, it is still recommended that positive samples must be further analyzed using a quantitative drug-specific analysis method.

After analyzing two qualitative tests, our results reinforced that SNAP duo beta-tetra ST test is able to detect on-farm beta lactam and tetracycline residues in cow milk. Therefore, these data pointed this kit as feasible to be used as part of antimicrobial residues control programs on properties. Interestingly, SNAP duo test kit could be useful for verification of beta lactam and tetracycline residues in raw mixed milk samples from individual cows treated for mastitis before processing the milk.

On the other hand, the results of Eco test BT pointed to the need for additional studies to ensure sensitivity, quality, and effectiveness to detect antibiotic residues in raw milk samples due to false positive results obtained. Furthermore, although there are several methods of rapid screening of antimicrobial residues in milk, it should be emphasized the importance of the establishment of food safety protocols on farm, that include awareness of producers about sanitary hygienic procedures to prevent the occurrence of bovine mastitis. In order to contribute to the control of antibiotic residues in milk and consequently to protect the health of the milk consumers, the suitable use of antibiotics to dairy cattle and the attendance to the withdrawal period of milk for human consumption to avoid antimicrobial residues in milk are also extremely important actions.

\section{Conclusion}

The SNAP duo Beta-Tetra ST® kit was presented as an easy-to-use field tool, fast, convenient and without the need for refrigeration and secondary equipment. The Eco Test BT®, presented as a difficult to use field tool, fragile, needs dexterity for execution and cooling. However, in the industry it may be a good choice as a screening test. This test pointed out the need for further studies to define its efficacy of to allow widespread use.

\section{Acknowledgment}

This project was financed by FAPERJ (Research Project No. E-26 / 111.150 / 2013), with the support of Universidade Federal Fluminense (UFF). We also thank CAPES for the scholarship, CNPq, FAPERJ and PESAGRO-RIO for laboratory support.

\section{References}

1. http://www.agricultura.gov.br/assuntos/politica-agricola/todaspublicacoes-de-politica-agricola/projecoes-do-agronegocio/ projecoes-do-agronegocio-2017-a-2027-versao-preliminar-25-07-17. pdf/.\%20Access\%2018\%20December\%202016.

2. Schwendel BH, Wester TJ, Morel PC, Tavendale MH, Deadman C, et al. (2015) Invited review: Organic and conventionally produced milk - an evaluation of factors influencing milk composition. J Dairy Sci 98(2): 721-746.

3. Grooms DL, Norby Bo, Grooms KE, Jagodzinski EN, Erskine RJ, et al. (2015) Short communication: Use of the BetaStar Plus assay for detection of ceftiofur antimicrobial residues in milk from individual cows following intramammary treatment for mastitis. J Dairy Sci 98(9): 6270-6277.

4. Ruegg PL (2012) New perspectives in udder health management. Vet Clin North Am Food Anim Pract 28(2): 149-163.

5. Schmidt T, Kock MM, Ehlers MM (2015) Diversity and antimicrobial susceptibility profiling of staphylococci isolated from bovine mastitis cases and close human contacts. J Dairy Sci 98(9): 6256-6269. 
6. Gomes F, Henriques M (2016) Control of bovine mastitis: old and recent therapeutic approaches. Curr Microbiol 72(4): 377-382.

7. Royster E, Wagner S (2015) Treatment of mastitis in cattle. Vet Clin North Am Food Anim Pract 31(1): 17-46.

8. Olatoye IO, Daniel OF, Ishola SA (2016) Screening of antibiotics and chemical analysis of penicillin residue in fresh milk and traditional dairy products in Oyo state, Nigeria. Vet World. 9(9): 948-954.

9. Lee MH, Lee HJ, Ryu PD (2001) Public health risks: chemical and antibiotic residues. Asian Austral J Anim 14(3): 402-413.

10. Arsand JB, Jank L, Martins MT, Hoff RB, Barreto F (2016) Determination of aminoglycoside residues in milk and muscle based on a simple and fast extraction procedure followed by liquid chromatography coupled to tandem mass spectrometry and time of flight mass spectrometry. Talanta 154(1): 38-45.

11. Girardi C, R Odore (2008) Pharmacological treatments and risks for the food chain. Vet Res Commun. 32(1): 11-18.

12. BRASIL (2013) Ministério da Agricultura, Pecuária e do Abastecimento. Secretaria de Defesa Agropecuária. Instrução Normativa n 7, de 27 de março de. Plano Nacional de Controle de Resíduos em produtos de origem animal. Diário Oficial da União de 03 de abril de, Brasília.

13. MERCOSUR( 2000) Reglamento técnico MERCOSUR metodologías analíticas, ingesta diaria admisible y límites máximos de residuos para medicamentos veterinarios en alimentos de origen animal MERCOSUR/GMC/RESOLUCION nำ 54 .

14. Guo P, Chen Y, Yue C, Yu G (2017) Simultaneous determination of clavulanic acid and tazobactam in bovine milk by HPLC. Food Addit Contam Part A Chem Anal Control Expo Risk Assess 34(4): 617-623.

15. Pereira RV, Siler JD, Bicalho RC, Warnick LD (2014) Multiresidue screening of milk withheld for sale at dairy farms in central New York State. J Dairy Sci 97(3): 1513-1519.

16. Waldron TT (2013) IDEXX SNAP® beta-lactam st validation for penicillin G detection. J AOAC Int 96(6): 1343-1349.

17. Bradley A (2016) Treatment of clinical mastitis in dairy cattle. Vet Rec 178(10): 238-239.

18. Cheng, R, Mantovani A, Frazzoli C (2017) Analysis of food safety and security challenges in emerging african food producing areas through a one health lens: the dairy chains in Mali. J Food Prot 80(1): 57-67.

19. Abouzied M, Driksna D, Walsh C, Sarzynski M, Walsh A, et al. (2012) Validation study of the BetaStar plus lateral flow assay for detection of beta-lactam antibiotics in milk. J AOAC Int 95(4): 1211-1221.

20. Reybroeck W, Ooghe S, De Brabander HF, Daeseleire E (2011) Validation of the Charm MRL-3 for fast screening of beta-lactam antibiotics in raw milk. J AOAC Int 94(2): 373-382.

21. Le Breton MH, Savoy-Perroud MC, Diserens JM (2007) Validation and comparison of the Copan Milk Test and Delvotest SP-NT for the detection of antimicrobials in milk. Anal Chim Acta 586(1-2): 280-283.
22. Hennart SL, Faragher J (2012) Validation of the Delvotest SP NT. Performance tested methods (SM) 011102. J AOAC Int 95(6): 18071815.

23. Tian H, Wang J, Zhang Y, Li S, Jiang J, et al. (2016) Quantitative multiresidue analysis of antibiotics in milk and milk powder by ultraperformance liquid chromatography coupled to tandem quadrupole mass spectrometry. J Chromatogr B Analyt Technol Biomed Life Sci 1033-1034: 172-179.

24. Chiesa LM, Nobile M, Panseri S, Biolatti B, Cannizzo FT, et al. (2016) A liquid chromatography-tandem mass spectrometry method for the detection of antimicrobial agents from seven classes in calf milk replacers: validation and application. J Agric Food Chem 64(12): 26352640 .

25. Samanidou V, Michaelidou K, Kabir A, Furton KG (2017) Fabric phase sorptive extraction of selected penicillin antibiotic residues from intact milk followed by high performance liquid chromatography with diode array detection. Food Chem 224: 131-138.

26. Guimarães FF, Manzi MP, Joaquim SF, Richini-Pereira VB, Langoni H (2017) Short communication: Outbreak of methicillin-resistant Staphylococcus aureus (MRSA) -associated mastitis in a closed dairy herd. J Dairy Sci 100(1): 726-730.

27. Martini CL, Lange CC, Brito MA, Ribeiro JB, Mendonça LC (2017) Characterisation of penicillin and tetracycline resistance in Staphylococcus aureus isolated from bovine milk samples in Minas Gerais, Brazil. J Dairy Res 84(2): 202-205.

28. Kneebone J, Tsang PC, Townson DH (2010) Short communication: Rapid antibiotic screening tests detect antibiotic residues in powdered milk products. J Dairy Sci 93(9): 3961-3964.

29. Fejzic N, Begagic M, Šerić-Haračić S, Smajlovic M (2014) Beta lactam antibiotics residues in cow's milk: comparison of efficacy of three screening tests used in Bosnia and Herzegovina. Bosn J Basic Med Sci 14(3): 155-159.

30. BRASIL (2003) Agência Nacional de Vigilância Sanitária. Gerência Geral de Alimentos. Resolução RDC n 253, de 16 de setembro de. Programa de Análise de Resíduos de Medicamentos Veterinários em Alimentos de Origem Animal - PAMVet. 2003. Diário Oficial da União de 18 de setembro de. Brasília.

31. Pacheco-Silva E, Souza JR, Caldas ED (2014) Resíduos de medicamentos veterinários em leite e ovos. Quim Nova 37(1): 111-122.

32. Prado CK, Ferreira FD, Bando E, Machinski M Jr (2015) Oxytetracycline, tetracycline, chlortetracycline and doxycycline in pasteurised cow's milk commercialised in Brazil. Food Addit Contam: Part B Surveill 8(2): 81-84.

33. Breen JE, Bradley AJ, Green MJ (2009) Quarter and cow risk factors associated with a somatic cell count greater than 199,000 cells per milliliter in United Kingdom dairy cows. J Dairy Sci 92(7): 3106-3115. 
CC (i) This work is licensed under Creative
Your next submission with Juniper Publishers will reach you the below assets

- Quality Editorial service

- Swift Peer Review

- Reprints availability

- E-prints Service

- Manuscript Podcast for convenient understanding

- Global attainment for your research

- Manuscript accessibility in different formats

( Pdf, E-pub, Full Text, Audio)

- Unceasing customer service

Track the below URL for one-step submission https://juniperpublishers.com/online-submission.php 